\title{
A BASIC LAND SALE AGREEMENT SOFTWARE: EXPLOITING ICT IN LEGAL PRACTICE IN NIGERIA
}

\author{
Oluwaseun Samson Fapetu ${ }^{1}$ (1D and Elijah Adewale Taiwo ${ }^{2}$. \\ ${ }^{1}$ Law Teacher, Faculty of Law, Adekunle Ajasin University, Akungba, Akoko, Ondo State, Nigeria \\ ${ }^{2}$ Professor and Dean, Faculty of Law, Adekunle Ajasin University, Akungba, Akoko, Ondo State, Nigeria
}
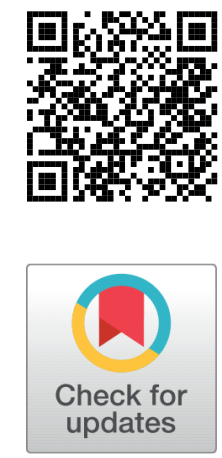

\section{ABSTRACT}

The use of Information Communication Technology (ICT) has permeated every profession, sector and facet of life. Although it has been slow in its application to legal practice in Nigeria, the prospect of ICT in law is promising and unending and it has resulted in the field of Artificial Intelligence (AI) and Law. AI and Law has many branches of which legal document automation forms an important part with high applications to drafting agreements. The paper examines the functionality of a programme written by the first author that automatically generates land sale agreements between natural persons, with the aim of ascertaining if the programme conforms with the appropriate provision of applicable laws. The paper examines the laws applicable to land sale agreements in Nigeria and finds that the document produced by the programme conforms with the provisions of these Laws. The paper also examines the issues that may arise in the use of the programme or similar programmes.

Received 4 July 2021

Accepted 19 July 2021

Published 31 July 2021

DOI $10.29121 /$

granthaalayah.v9.i7.2021.4081

Funding: This research received no specific grant from any funding agency in the public, commercial, or not-for-profit sectors.

Copyright: (C) 2021 The Author(s). This is an open access article distributed under the terms of the Creative Commons Attribution License, which permits unrestricted use, distribution, and reproduction in any medium, provided the original author and source are credited.

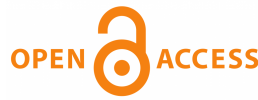

Keywords: ICT and Law, AI and Law, Legal Document Automation, Computer Applications to Law, Computer Programming in Law

\section{INTRODUCTION}

On the $3^{\text {rd }}$ of July, 2020, Oladapo Daniel Oyebanjo popularly known by his stage name, "D"Banj" filed a case against Seyitan Babatayo for a claim of 1.5 Billion Naira through his counsel Mike Ozekhome (SAN) at the High Court of the Federal Capital Territory, Abuja. ${ }^{1}$ What however got the attention was not the 1.5 Billion Naira Claim but the manner in which the claim was written in the court process. The 1.5 billion Naira claim was divided into two claims, a 1 billion Naira, general damages and a 500 million Naira, aggravated, punitive and exemplary damages. However, the former claim was written as "One Billion Million Naira".

\footnotetext{
${ }^{1}$ Akinkuotu E., “Rape: D”Banj Sues Accuser for N1.5bn”, The Punch Newspaper, 4 July, 2020.

2 See the Tweet of Postsubman (@postsubman), "-Just in: Lawyer and Human Rights Activist- Mike Ozekhome sues Dbanj's Accuser- Seyitan for 1.5billion Naira” Twitter Inc 3 July, 2020 available at $<$ htt ps://twitter.com/Postsubman/status/1279102436909735937?s=19> accessed 11 March 2021.
} 
The error in the claim became a trending topic on "Twitter Nigeria" on the same day that is, $3^{\text {rd }}$ of July 2020. At around 10 o"clock in the evening, "Mike Ozekhome" and "One Billion Million" were trending topics 6 and 14 on the trends of Twitter Nigeria. $^{3}$ The fact that the process emanated from the office of a well-known Senior Advocate of Nigeria shows the infallibility of man no matter how highly experienced or dutiful s/he is. This is where Information and Communication Technology (ICT) comes in.

The processing power of computer systems, the ubiquity of the internet and the cognitive abilities of Artificial Intelligence have made ICT applicable in all spheres of life. However, the legal sector has been slow in incorporating high end ICT, in fact Martin remarks that transactional lawyers have been "notoriously slow" in integrating technology in their practice. ${ }^{4}$ This reality is worse in Nigeria where the biggest arguable use of technology in legal practice is the automated services of some states" land registry and the yet to be efficiently running platform of the Corporate Affairs Commission. ${ }^{5}$

In advanced countries, the trend has changed in recent years as there has been a massive use of ICT in legal practice. Of course, this discourse is not about using word processing programmes to make legal documents but rather application of advanced ICT tools famously termed "Artificial Intelligence (AI)". The concept of AI has been defined as using computers to automate task normally require human intelligence. ${ }^{6}$ It has also been defined as emphasising technology that automates specific type of task thought to require intelligence when people perform them. ${ }^{7}$ Thus, AI transcends using computer system to perform tasks but goes a step further for the computer process data using cognitive methods to perform tasks that will ordinarily involve human intelligence.

Lately, there is a new branch of research termed "AI and Law" which focuses on the application of AI to law. More comprehensively, Surden defines AI and Law as "the application of computer and mathematical techniques to make law more understandable, manageable, useful, accessible, or predictable". ${ }^{8}$ Simply put, AI and Law deals with computer methods used in the practice of law or in the process of information used in legal practice. There are many of such methods, in fact, 35 of such applicable methods in law is identified. ${ }^{9}$

\footnotetext{
${ }^{3}$ Trending topics of Twitter Nigeria available at <https://getdaytrends.com/nigeria/2020-07-03/ 22/> accessed 11 March 2021.

${ }^{4}$ Martin K., "Emerging Contract Technology: Automating the Contract Life-Cycle". Legal Executive Institute 29 April, 2015 available at <https://www.legalexecutiveinstitute.com/emerging-contract-te chnology-automating-the-contract-life-cycle/> accessed 11 March 2021.

${ }^{5}$ These submissions are based on the personal experience of the Authors.

${ }^{6}$ Russell S., Norvig P., Artificial Intelligence: A Modern Approach, 3rd Ed (Prentice Hall, New Jersey, 2020) 1.

7 Ibid 2.

${ }^{8}$ Surden H., "Artificial Intelligence and Law: An Overview" (2019) 35 Ga. St. U. L. Rev. 1327

${ }^{9}$ See Emerj, "AI in Legal Practice- A Comprehensive View of 35 Current Applications" (2021) Business Intelligence and Analytics available at <https://emerj.com/ai-sector-overviews/ai-in-law-legal-p ractice-current-applications/> accessed 12 March 2021.
} 
One of these methods is "legal document automation" which is the process of using AI to draft legal documents. ${ }^{10}$ This paper is a theoretical analysis of a simple programme written by the first author to draft simple land sale agreement which will fulfil the basic requirements of a land sale agreement in Nigeria. As much as this paper may sound technically as a scientific exploit than a legal research, this is a research in the emerging field of AI and Law and fittingly a legal research. The paper will exploit the tenets of legal document automation, exploring the technical, ethical and legal issues that may arise in the development and use of this AI method. The paper will also examine the essentials of a land sale agreement before justifying the compliance of the programme to these essentials. It will also examine how the programme addresses the already discussed technical, ethical and legal issues and will conclude on the prospects of the programme and other similar programmes in Nigerian legal practice. Technical details of the programme will be explained also to elucidate on the functionality of the programme.

\section{LEGAL DOCUMENT AUTOMATION}

As explained above, legal document automation is one of the methods of AI and Law which involve the use of AI to make competent legal documents. The method is one of the earliest methods of AI and Law, Betts and Jaep in an article highlight the history of legal document automation particularly contract drafting softwares. ${ }^{11}$ Word processing software in the 1980s and 1990s was arguably the emergence of legal document automation as this software offered simple computer file management systems, automatic numbering tools, basic "master documents," macros, and document "merge" functions. ${ }^{12}$ With the use of word processing software, drafting of legal document became less tedious, cheaper, more organised and productive as less time was required in making similar documents. ${ }^{13}$

As earlier emphasised in the introduction section, AI and Law transcends merely processing information with the use of computers, the processing must involve intelligence for it to qualify as an AI method. Thus, it can be argued that the use of word processing software in the 1980s and 1990s did not qualify as a method of AI and Law. However, the development of "expert drafting systems" in the latter years of 1990s whereby a document is produced using "logic tree" from a series of answer supplied to the system ${ }^{14}$ satisfies the requirement of intelligence and the beginning of legal document automation.

These expert drafting systems however were critiqued for their text being hard coded and inflexible and preventing the user from making changes after the produc-

\footnotetext{
${ }^{10}$ Ibid.

${ }^{11}$ Betts K. D., Jaep K. R., “The Dawn of Fully Automated Contract Drafting: Machine Learning Breathes New Life into a Decades-Old Promise" (2017) 15(1) Duke Law \& Technology Review 218-221.

12 Ibid. See also, Dunn D., "Easy Document Assembly with Word Processors", (1995) 83 ILL. B.J. 93.

${ }^{13}$ Dunn D. op cit at 93.

${ }^{14}$ Guthrie K. I., “Document Assembly Software Systems”, (1995) 9 Probate \& Property 27-28.
} 
tion of the document. ${ }^{15}$ "Document assembly engines" quickly followed the drafting systems and these engines allowed for modification and combination of drafting templates with other texts. ${ }^{16}$ As much as this allowed for more flexibility, it takes away the speed and ease offered by expert drafting systems.

Machine learning has provided for the betterment of these programmes ${ }^{17}$; however, machine learning is not a focus of this paper. The use of these programmes has generated some technical, ethical and legal issues which the paper will thereafter explore.

\section{TECHNICAL, ETHICAL AND LEGAL ISSUES GENERATED BY LEGAL DOCUMENT AUTOMATION}

Although there are three different categorisations of the issues raised by the use of legal document automation, that is technical, ethical and legal issues. All these issues will be addressed under one heading as these issues just like the technology itself are newly emerging. Some of these issues may also not be strictly tailored under any of these categorisations and may reflect in two or even all of the categorisations.

\subsection{INFLEXIBLE OF LEGAL DOCUMENT AUTOMATION AND LIMITATION OF INGENUITY}

As explained above legal document automation requires hard coding of text which the underlying algorithms combine with "limited universe of questions and answers". ${ }^{18}$ This makes the programme very inflexible and predictable unlike documents made by lawyers who may choose to change the style, diction, structure or even format of the document. However, this issue may not be so consequential as most lawyers and sometimes law firm have a style they use and editing old prototypes of documents is not also uncommon amongst lawyers.

\subsection{INTELLECTUAL PROPERTY IN COMPUTER PROGRAMMES}

Software or computer programme usually take a lot of time and effort to make especially when the programme is designed to act intelligently. Unfortunately, a line of code may be written significantly different to produce the same or similar results. This makes it easy for efforts utilised on computer programme to be copied. The fact that there are several programming languages to code with ${ }^{19}$ makes this even

\footnotetext{
${ }^{15}$ Ibid.

${ }^{16}$ Ibid.

${ }^{17}$ See Adams K., 'some Thoughts on LexPredict', Adams on Contract Drafting, 2 July, 2015, available at <http://www.adamsdrafting.com/some-thoughts-on-lexpredict/> accessed 12 March, 2021; Lat D., "The Future of Law and Technology: An Interview with Bloomberg BNA's David Perla", Above the Law 27 August, 2015, available <http://abovethe law.com/2015/08/the-future-of-law-and-technology-aninterview-with-bloomberg-bnas-david-perla/> accessed 12 March 2021.

${ }^{18}$ Betts K. D., Jaep K. R Ibid, 221.

${ }^{19}$ These include popular ones like Python, Java, C, C++, PHP, Ruby, J\# and several hundreds of other programming languages.
} 
worse, as a competent programmer vast in 2 different languages may copy the concept and structure of a working programme and duplicate it in another programme and it will be difficult to relate the programmes except for the product. Worse still, legal document automation as explained above usually use hard coded text to produce its result, thus, a change in the wordings and style of the copied programme will produce a significantly different result from the original programme.

Under Nigerian laws, computer programmes or software are only explicitly protected by copyright. ${ }^{20}$ However, due to the nature of the protection of copyright, ${ }^{21}$ infringement of computer software may pass as original work and more so, it may prove herculean to prove the infringement. It has been argued that computer programmes may implicitly be protected under the Patents and Designs Act. ${ }^{22}$ A review of section 1 of the Patents and Designs shows computer programmes may not be protectable under this statute. Section 1(1)(b) and (c) specifically provides that:

"b. an invention results from inventive activity if it does not obviously follow from the state of art, either as to the method, the application, the combination of method, or the product which it concerns, or as to the industrial result it produces.

c.an invention is capable of industrial application, if it can be manufactured or used in any kind of industry..."

from the wordings of the legislation, it is obvious that protection covers not only manufactured inventions but also inventions which with unique combination of methods that can be used in any kind of industry. It will however be subject to the Patent and Design Office of Nigeria regarding the legal sector as an industry.

Protection of software under patent may be more appropriate as patent has more stringent criteria for protection under patents than copyrights. ${ }^{23}$ Also, patents is more restrictive than copyright in the protection of which an infringement may not create a new copyright even if novel unlike what is obtainable under copyright. ${ }^{24}$ It should be noted, however that the term of copyright accords more protection than patents. ${ }^{25}$

This paper posits that this may become an apparent problem as more sophisticated computer programmes are written not just in the field of AI and Law but in any other field which the protection offered under copyright will be inappropriate for adequate protection while the term of protection under patents may be too short.

\footnotetext{
${ }^{20}$ Section 39 of the Copyright Act, 2014

${ }^{21}$ Section 1(2) Ibid.

22 Jegede O., "Overview of Software Protection in Nigeria” Nigerian Law Intellectual Property Watch Inc. 3 October, 2021 available at <https://nlipw.com/overview-of-software-protection-in-nigeria-byolusola-jegede/> accessed 12 March 2021.

${ }^{23}$ While the requirement of copyright is novelty, expression and fixation which can easily be fulfilled, patent protection requires novelty, non-obviousness, inventive step and industrial application which may require the applicant to prove that the invention is more than just a mere novel invention.

${ }^{24}$ A comparison of Section 1 of the Patents and Designs Act with Section 1 of the Copyright Act shows that while an infringement of a copyright is protected under the latter, an infringement may not qualify for protection under patents.

${ }^{25}$ The first schedule to the Copyright stipulates a term of seventy years after the end of the year in which the author dies while Section 7(1) of the Patents and Designs Act stipulates that a patent will expire at the end of the twentieth year from the date of the filing of the relevant provisions.
} 
The paper in passing advocates for a new sui-generis regime that will provide adequate protection for computer programmes.

\subsection{LIABILITY FOR MISTAKES AND ERRORS IN THE DOCUMENT}

Ordinarily, when documents are made by lawyers, the lawyer takes responsibility for any loss arising to the client if he makes an error or mistake while making the document. A lawyer may be liable for negligence for any loss or damage a client makes due to an error or mistake in a legal document. Even in unlikely circumstances where the loss may not be actionable in court, the lawyer still owes a fiduciary relationship and will still be liable to face a disciplinary forum. ${ }^{26}$

The use of legal document automation raises the issue of liability. The idea behind the technology is for the creation of legal documents without the input of the legal practitioner especially if the programme is designed in a form whereby the client can get the document without an interaction with the lawyer, for example, where a contract can be made by a client by merely inputting certain facts on the lawyer's website and the document will be automatically generated without the interaction of the lawyer. It can be argued that since the programme is likely written by a computer programmer and not the lawyer, should the lawyer take liability of an error he did not make?

This paper argues that the issue should be resolved in two separate veins. The first being liability for the fiduciary duty owed by the lawyer to the client for employing the use of an error-prone computer programme in his practice. While the second will be an action for negligence of the computer programme for making the software that resulted in the lawyer being fiduciarily liable to his client.

\subsection{OWNERSHIP OF COMPUTER PROGRAMME AND THE ETHICAL IMPLICATION}

Rule 3 (1) of the Rules of Professional Conduct for Legal Practitioners (PRCLR) provides that

“3 (1) A lawyer shall not-

1. aid a non-lawyer in the unauthorised practice of the law;

2. permit his professional services or his name to be used in aid of, or to make possible, the unauthorized practice of law by any person not qualified to practice or disqualified from practice;

3. share legal fees with a non-lawyer..."

Legal automation will undoubtedly enhance the efficiency of a lawyer as it will reduce the time utilised in making documents that are seemingly repetitious in nature. However, since it is computer programmers that make this automation programmes and

\footnotetext{
${ }^{26}$ Cooper B. P., "When Clients Sue Their Lawyers for Failing to Report Their Own Malpractice" (2015) 44(441) Hofstra Law Review 442. See Rule 14(5) of the Rules of Professional Conduct for Legal Practitioners, 2007.
} 
not lawyers, the ownership of these programmes may belong to programmers and not lawyers. It is logical that the computer programmer would have gotten instructions and explanation of legal concepts before the former can make an efficient programme that will be applicable in legal practice, ownership may still belong to the programmer.

Ownership of a computer programmer in Nigeria is subject to the Copyright Act as well as the principles of a simple contract under the Common law. Section 10 (1) and (2) of the Copyright Act gives an independent contractor (subject to assignment, license or terms of engagement) ownership in any copyright work. The implication of this is that unless with the terms of the engagement between a lawyer and a commissioned computer programmer, any programme developed belongs to the programmer.

Additionally, the parties may by the terms of the contract agree to share any revenue generated through the use of the programme as the programmer may be unwilling to take a specific consideration for the programme especially where same is ingenious or revolutionary. In these aforementioned instances, the ownership of legal document automation software may be inconsistent with the above cited provisions of the RPCLR as a lawyer must instruct and explain the form of a legal document to a programmer before the latter can make an appropriate programme for same. Also, the task of developing a programme may not be adequately compensated with a fixed time payment especially when there will be consistent recurrent charges on clients for the use of the programme.

\subsection{OTHER ETHICAL ISSUES IN THE USE OF LEGAL DOCUMENT AUTOMATION}

Betts and Jaep argue that the dynamism in law may lead to ethical issues in the use of computer programmes in legal practice. ${ }^{27}$ They posit that when there is a change in law, a programme may become redundant. There will be a need for periodic recoding of such programmes, which will likely require technical expertise of a computer programme. This may result in a lawyer who has been consistently used to automatically generating legal documents to resort to switch back to manual drafting, which will prove more lofty and frustrating producing 'significant inefficiencies". ${ }^{28}$

\subsection{AI AND LAW MAY MAKE LEGAL PRACTICE OBSOLETE}

Legal document automation software that writes documents, lawyers use several hours to write in a few minutes, the ease and speed of these programme makes it a desirable tool. Additionally, programmes are now being designed to learn and improve on the quality of their productivity, a process called machine learning. ${ }^{29}$ It

\footnotetext{
${ }^{27}$ Betts K. D., Jaep K. R Ibid, 222.

28 Ibid.

${ }^{29}$ Machine learning is a process where the processor uses a complex system of algorithms to process data and provide feedback to further improve its algorithms. Love D., "What the Heck is Machine
} 
should also be noted that clients are always looking for ways to cut cost on legal services. ${ }^{30}$ Many Nigerians resort to tout, "business centres" and paralegals to help them facilitate cheap legal document notwithstanding the risk of the documents being incompetent.

With legal document automation, the trend may prove worse as a programmer that have previously developed programmes for lawyer may decide to improve on the programme and commercialise it for public use. Such a commercial product will be very cheap compared to what a competent lawyer will charge and since quality is assured from these programmes, people may refuse to engage lawyers to make legal documents for them. Triantis opines that the global recession has made clients both natural persons and corporate institutions look for cheaper yet better legal service. ${ }^{31}$ He further warns that "If lawyers seek only to compete on price, then the survival of transactional legal practice as a distinct profession will hinge on the flimsy regulation of unauthorized legal practice, and will ultimately fail". ${ }^{32}$

The issue raises a dilemma, while some legal services become easily accessible, fast and have better quality due to the use of legal document automation and machine learning. In the alternate vein, this will lead to reliance on computer programmes for the making of these documents leading to the obsoleteness in the practice of drafting such documents and ultimately loss of remuneration for lawyers.

\section{ESSENTIALS OF A LAND SALE AGREEMENT IN NIGERIA}

The main subject of this paper is a programme written by the first author that automatically generates a land sale agreement using a few essential facts which can be inputted by either a lawyer or a client that needs the document. Before an analysis is made into the technicalities and functionality of the programme, it is pertinent to examine the rudiments an agreement must fulfil to qualify as a basic land sale agreement.

Like most simple contracts in Nigeria, a land sale agreement is governed by the common law. Elementarily, this means that the contract must have offer, acceptance, consideration, intention to enter legal relationship and capacity to contract. ${ }^{33}$ These are facts that may not be apparent on the face of the agreement though there may be pointers in the face of the agreement from which some of these facts may be deduced. There are, however some more specific requirements that deals with the form of the agreement.

- Agreement must be in writing and signed:

Learning?", BUS. INSIDER 3 May, 2014 available at <http://www.businessinsider.com/machine-learni ng-2014-5> accessed 13 March 2021.

30 Triantis G. G., "Improving Contract Quality: Modularity, Technology, and Innovation in Contract Design" Stanford Law School (2014) available at <http://ssrn.com/abstract=2306209> accessed 13 March, 2021.

${ }^{31}$ Ibid.

${ }^{32}$ Ibid.

${ }^{33}$ See Sagay I. E., Nigerian Law of Contract, (Sweet and Maxwell, London 2018). 
By virtue of the Statutes of Fraud, ${ }^{34}$ all contract for sale or any other disposition of land or interest in land must be in a written memorandum or note and must be signed by the party to be charged or through an authorised person. ${ }^{35}$ The Statute of Fraud has been superseded in many states of the federation by specific legislations regulating though it should be noted the requirement of the contract being contained in a note or memorandum and same must be signed by the party or the authorised person instead. ${ }^{36}$

It should be, however noted that these legislations are silent about the form in which the agreement should take. The Court of Appeal in the case of Adeniran v Olagunju ${ }^{37}$ stated per Justice Amaizu J.C.A that;

"I have mentioned earlier that the law requires the evidence of a transaction in a sale of land to be in a note or a memorandum. It is necessary to mention also that no special form is prescribed for the note or memorandum. However, from the authority of decided cases particularly in Hamilton v Kofi Mensah (1937) 3 WACA 224 a document that will satisfy the description of a note or memorandum within the meaning of the statutory provision must contain the following details-

1. names of the parties or enough description of the parties.

2. the ample description of the subject matter of the contract.

3. the consideration for the alleged contract and

4. the document must contain the signature of the party to be charged or that of his agent or a representative duly authorised by him."38

The interpretation given to the requirement of an agreement for land sale agreement under the Statute of Fraud and other similar legislation is quite succinct. Although, it should be emphasised that most lawyer adopt a style that provide the names and address of the parties, a clear description of the property, the consideration, signature of all the parties to the agreement and at least two attesters to the agreement.

- Illiterate jurat where one of the parties is an illiterate:

The law usually protect illiterate who are parties to an agreement to ensure the illiterate understand the implications of the agreement they are entering into thereby protecting the illiterate from possible fraud. ${ }^{39}$ This protection was made compulsory for any document executed by an illiterate. ${ }^{40}$ The form this jurat is to take is to state

\footnotetext{
${ }^{34}$ Statute of Fraud Act, 1677. A statute of general application that is, statutes in force in the England as at 1st of January, 1900 which became applicable to Nigeria by virtue of the Section 14 of the Supreme Court Ordinance, 1914.

${ }^{35}$ Section 4, Statute of Fraud Act.

${ }^{36}$ Section 67(1) of Property and Conveyancing Law, 1956, Laws of Western Region of Nigeria; section 5(2) of Law Reform (Contract) Act, 2006, Laws of the Federal Capital Territory;

${ }^{37}$ (2002) FWLR, [pt. 87] 852, 840

38 Ibid.

${ }^{39}$ Dadem Y. Y., Property Law Practice in Nigeria, 2nd Ed (Jos University Printing Press Ltd, Jos, 2012) 20.

${ }^{40}$ See Illiterate Protection Laws of various states.
} 
the name and address of the person who makes the interpretation, a clause to show that the illiterate understands the content of the document before the execution of the document. ${ }^{41}$

- Agreement must be prepared by a legal practitioner

A land sale agreement or any document for sale or transfer of land is required to be prepared by a legal practitioner by virtue of Land Instrument Preparation Laws of states in Nigeria ${ }^{42}$ as well as the Legal Practitioners Act. ${ }^{43}$ This poses a problem for document for sale or transfer of property made with AI. A document made by AI is definitely not made by a legal practitioner and may fall short of this requirement. There is however the argument that if the legal document automation was used or authorised by a legal practitioner, then the lawyer can be said to have franked the document especially if his signature is appended on the AI generated document.

- Other conventional miscellaneous terms:

Although these terms do not directly affect the validity or form of a land sale agreement, they have become conventional in drafting to include them in any land sale agreement, they include;

1. Recitals which are not operational part of the agreement but an explanatory note to explain the intent of the parties in entering the agreement.

2. An indemnity clause to indemnify the purchaser(s) against any third-party claim on the property.

3. An optional deposit clause where the parties agree for the payment of a deposit that is liable to be forfeited if the purchaser defaults. ${ }^{44}$

4. A clause stipulating that the vendor(s) undertake to execute any document to perfect the assignment of right in the property to the purchaser(s).

\section{REVIEW OF THE BASIC LAND SALE AGREEMENT SOFTWARE}

The programme was written fully with Python ${ }^{45}$ language specifically version 3.81 . some internal and external modules were used in the implementation of the programme. The datetime internal module, specifically the date function of the module

\footnotetext{
${ }^{41}$ Dadem Ibid.

${ }^{42}$ An example is Section 5 of the Land Instrument Preparation Laws of Kaduna State, 1991

${ }^{43}$ Section 22(1)(d) of the Legal Practitioners Act, 2004.

${ }^{44}$ Edosa v Zaccala (2006) All FWLR [pt. 306] 909.

${ }^{45}$ Python is an interpreted, high-level, general-purpose programming language developed by Guido van Rossum. The current version is 3.10.0a6 released on the 1st of March, 2021 while the most recent stable version is 3.9.2 released on the 19th of February, 2021. Python documentation is available at $<\mathrm{h}$ ttps://docs.python.org>
} 
was used in specifying the execution date of an agreement. The choice function of the random module was also used to give the programme a bit of flexibility.

Python does not have a module or function to directly manipulate word document files $^{46}$, therefore an external library was installed using "pip installer" ${ }^{47}$. The external library installed is the python-docx ${ }^{48}$ which is a library for creating and updating Microsoft Word (.docx) files.

The Document function of the docx module of the python-docx library was used extensively in the programme to create word document files while the WD_ALIGN_PARAGRAPH and WD_LINE_SPACING functions from the docx.enum.text ; the WD_STYLE_TYPE of the docx.enum.style and the Pt function of the docx.shared module were used in styling and structuring the text generated by the programme.

The programme used basic logic, loops and conditionals to instruct the programme in manipulating results from inputs in creating a programme that can qualify as intelligent. The first author was also careful in naming variables used in the programme so it will be easily understandable for any future Pythonista or Pythoneer that may work to improve the programmer in the future. It should be pointed out that the programme can only produce documents between natural persons.

The programme being a code that will require several inputs before execution was written without the utilisation of defined classes but the programme utilised a lot of function to effectively remedy some inadequacies in the custom internal modules, methods and functions of Python.

\subsection{FEATURES OF THE PROGRAMME}

- Flexible date function for the date of execution of agreement:

Using the today function of the date method in the datetime module, the programme was written to automatically set the day of the execution of the agreement as the day the document was created. It should be noted that the date can be set to any specific date using just the date method of the datetime module using the year, month and date attributes, however, one must specify same at the back-end code, this can however be improved if the programme is run through a frontend programme that allows amendment of the present programme that will act as the backend.

- Unlimited number of parties:

The programme is designed to accommodate an unlimited number of parties either as vendors or purchasers. The programme is also tailored to pair each party with

\footnotetext{
${ }^{46}$ Usually save with the ".doc" or ".docx" extension and produced by word document programmes like Microsoft Word ${ }^{\mathrm{TM}}$.

${ }^{47}$ This is a package installer for Python language.

48 The current version of this library that is, 0.8 .10 was installed and used in the development of this programme. The documentation of this library is available at <https://python-docx.readthedocs.io/en /latest>.
} 
its respective address of the parties with their names and any other description. The programme also efficiently reflects these details appropriately where they are required in the agreement.

- Grammatical concord of agreement text:

The programme was designed to be intelligent to know what verb it should use in accordance to the number of parties especially in the main body of the agreement. For loops with logic involving conditional statement to help the programme determine the number of parties involved in the transaction and the appropriate text to display.

- Conformity with basic requirement of a land sale agreement:

The document produced by this programme conforms significantly to the above examined basic requirements of a land sale agreement. The document produced by the programme contains the names and addresses of the parties, a recital, the consideration, execution by all the parties to the agreement before two witnesses as well as miscellaneous terms which include an optional deposit, indemnification, perfection of title, and applicable law clauses.

More interestingly, the programme in conformity with the provisions of the Land Instrument Preparation Laws of states in Nigeria makes it mandatory to provide the name of the legal practitioner to frank the agreement and it automatically inserts the "esq." title as a suffix to the name. The programme also drafts an illiterate jurat before the execution clause in the event that any of the parties is an illiterate.

- Applicable for transactions over family properties:

The programme is also built to be able to draft agreement over family properties with the appropriate recital and terms. The programme automatically selects the first vendor as the family head and the others as the principal members of the family. Where there is only one vendor, the vendor is positioned as the Head of the family who has the authority of the members of the family to sell the family property.

\subsection{LIMITATIONS OF THE PROGRAMME}

1. The programme is just a standalone backend programme with no frontend programme to give it a good visualisation, this also means it will be unusable on a computer that does not have Python installed on it as well as the python-docx library. The programme may be hard for a person without the knowledge of Python programming language to run it. The programme cannot also be run on a server as it has not been written to be assessible on a server, thus the programme cannot be run remotely. Rewriting the programme as a programme to be used with a web development framework like Flash or Django ${ }^{49}$ will allow a

\footnotetext{
${ }^{49}$ Flask and Django are web development frameworks for Python that allows Python Programmes interact with web pages and act as servers for a webpage.
} 
better visualisation as well as solve all the aforementioned problem. A graphical user interface can also be an alternative to deploying the programme for use on a webpage, however, developing a graphical user interface may be more expensive and cumbersome than simply using a webpage as the interface for visualisation. Using a web development framework with the programme will also expose the programme to the dynamism of a webpage.

2. The programme is only available for transactions between natural person and not corporate persons. This is due to the complexity in the execution of contracts by corporate entities. The programme was designed to generate the document after a series of questions are answered by the user. It will prove cumbersome and timewasting to properly execute an agreement for a corporate person. ${ }^{50}$ However, if the programme is developed to worke with a webpage providing visualisation, it will be easy to effect execution by a corporate person using different type of input methods instead of questions and answer that the programme currently uses.

3. The programme does not allow customisation as the user cannot change the main text, syntax and language use as the programme is at best a backend programme. Without a front-end programme that will change the text produced by the backend, the programme will always yield similar result except if the main programme is edited. The solution proffered above that is, using the programme with a web development framework will also solve this limitation.

4. the final limitation of this programme is machine learning which will make the programme not only intelligent but also learn to better its productivity by itself, thus the programme will be able to auto-rewrite its code so it can become more efficient.

Notwithstanding the above listed limitations, documents produced by the programme supersedes the basic requirement of a land sale agreement. It should be noted that it is not unusual for a programme to have bugs so it is possible for certain syntactical bug is produced in the text of the produced document.

\section{CONCLUSION AND RECOMMENDATIONS}

It is imminent that most part of legal practice will become obsolete in the nearest future as intelligent computer programmes will be able to render these services using less time and less expensive resources. Computing or programming is not a conventionally part of the legal practice, however like natural languages, it takes only understanding, discipline and practice to be proficient in it.

The reviewed programme shows the prospect of AI in law and how the legal practice can be bettered with the acceptance of these technologies. If the incorporation

\footnotetext{
${ }^{50}$ The newly amended Company and Allied Matters Act, 2020 vide section 120 makes execution of a company even more complex as a company's can now execute an agreement through just one of its directors in the presence of a witness; a director and a secretary or through 2 of its directors.
} 
of $\mathrm{AI}$ is imminent, lawyers and legal researchers should not be mere spectators or users of these technologies. As explained above, the right in these programmes are governed by the law of contract and intellectual property and it is likely to be vested in computer programmers than lawyers. Thus, in the future it is very possible that the right to most legal services will be owned by computer programmers if the tide is not changed and lawyers and legal researchers take over the responsibilities of writing programmes for use in the legal practice.

It should emphasise that AI and Law is an established field of research in many universities in some countries, Nigerian universities are however still stuck in the teaching and research of substantive law, there should be a paradigm shift and some of the researches should be focus on the practical application of ICT especially AI in law. Flowing from this narrative, this paper hereby makes the following recommendations:

1. Legal researchers should be encouraged to focus on technical and practical application of ICT to legal practice.

2. The field of AI and Law should be incorporated into the curriculum of law more appropriately at post-graduate level with law graduate student with interest in programming, students from law related courses with intermediate or advanced knowledge in programming language(s) and graduate student of computer science, software engineering or similar courses with interest in making AI tools for legal practice should be target students. Also, Legal scholars and programming experts should draw a comprehensive curriculum for the field of AI and Law for adoption of by the Nigerian University Commission.

3. Faculties of law should encourage undergraduate to choose a career in the field of AI and Law or in the application of ICT in legal practice by incorporating it in the extra-curriculum activities of the undergraduate by floating ICT Clubs, competitions, periodic lectures and symposiums and student conferences on ICT related aspect of law.

4. Lawyers should accept and encourage the use of ICT tools in their legal practice and should be mindful of the implications of agreements they make for development of ICT tools on legal practice.

5. The Body of Benchers, the Bar Council as well as the Nigerian Bar Association should solicit for the enactment of legislation that will regulate and restrict the interest of non-lawyers in AI tools that provide legal services.

\section{REFERENCES}

Adams, K. (2015). Some Thoughts On Lexpredict. Adams On Contract Drafting.

Akinkuotu, E. (n.d.). Rape: D"Banj Sues Accuser For N1.5bn”, The Punch Newspaper.

Betts, K. D., \& Jaep, K. R. (2017). The Dawn Of Fully Automated Contract Drafting: Machine Learning Breathes New Life Into A Decades-Old Promise. Duke Law \& Technology Review, 15(1). 
Cooper, B. P. (2015). When Clients Sue Their Lawyers For Failing To Report Their Own Malpractice. Hofstra Law Review(441), 442-442.

Dadem, Y. Y. (2012). Property Law Practice In Nigeria.

Dunn, D. (1995). Easy Document Assembly with Word Processors.

Emerj, . ., \& Ai. (n.d.). Legal Practice- A Comprehensive View Of 35 Current Applications" (2021) Business Intelligence And Analytics Available At. Retrieved from <Https:// Emerj.Com/Ai-Sector-Overviews/Ai-In-Law-Legal-Practice-Current-Applications/>

The Future Of Law And Technology: An Interview With Bloomberg Bna's David Perla", Above The. (2015). Com/2015/08/The-Future-Of-Law-And-Technology-An-InterviewWith-Bloomberg-Bnas-David-Perla/>.

Guthrie, K. I. (n.d.). Document Assembly Software Systems", (1995) 9 Probate \& Property 27. Jegede, O. (2021). Overview Of Software Protection In Nigeria. Nigerian Law Intellectual Property Watch Inc.

Love, D. (2014). What The Heck Is Machine Learning? Businessinsider.Com/MachineLearning.

Martin, K. (2015). Emerging Contract Technology: Automating The Contract LifeCycle". Legal Executive Institute 29 April. Retrieved from AvailableAt<Https:// Www.Legalexecutiveinstitute.Com/Emerging-Contract-Technology-Automating-The -Contract-Life-Cycle/>

Postsubman, T. 0. (2020). "-Just In: Lawyer And Human Rights Activist- Mike Ozekhome Sues Dbanj's Accuser- Seyitan For 1.5billion Naira. Retrieved from AvailableAt<Https:// Twitter.Com/Postsubman/Status/1279102436909735937?S=19>

Russell, S., \& Norvig, P. (2020). Artificial Intelligence: A Modern Approach. Prentice Hall. Sagay, I. E. (2018). Nigerian Law Of Contract.

Surden, H. (2019). Artificial Intelligence And Law: An Overview. Ga. St. U. L. Rev, 1327-1327.

Triantis, G. G. (2014). Improving Contract Quality: Modularity, Technology, And Innovation In Contract Design. Stanford Law School. 